\title{
Strategic Purchasing to Improve Health System Performance: Key Issues and International Trends ${ }^{1}$
}

\author{
- \\ PURCHASING \\ Reinhard Busse, MD, MPH \\ Professor and Chair, Department of Health Care Management, \\ Berlin University of Technology \\ Associate Head for Research, European Observatory on Health Systems and Policies \\ Josep Figueras, MD, MSc \\ Director, European Observatory on Health Systems and Policies \\ Ray Robinson, $\mathrm{PHD}$ \\ Professor of Health Policy, London School of Economics and Political Science \\ Elke Jakubowski, MD, MSc \\ World Health Organization - Regional Office for Europe
}

\section{Introduction}

All health systems exercise some form of purchasing, which, in its most basic form, constitutes the allocation of funds to provider organizations. When purchasing goes beyond the simple reimbursement of products and services and is aligned to societal healthcare needs and wishes, it has the potential to play a key role in determining a health system's over- all performance. However, no single organizational model of purchasing can, or should, be applied to all health systems. Purchasing arrangements must be determined chiefly by each country's main form of healthcare funding and provision.

Purchasing goes well beyond the mere contracting of providers. It includes the central role played by citizens and their 
governments as well as by providers' organizational forms. A central lesson derived from our analysis is that if policy-makers are to achieve their desired results, they need to take a broad systems approach to purchasing and act upon all the various components of the purchasing function. If purchasing is narrowly focused on individual elements such as contracts, payment systems or provider competition, it will not reach its full potential. For instance, the introduction of a new case mix-based payment system to improve efficiency will succeed only if providers can count on the managerial and organizational ability to respond to these new financial incentives and if the health interventions financed through the new payment system are informed by cost and effectiveness evidence and respond to the health needs and priorities of the specific population being served.

A definition of strategic purchasing should reflect this systemic approach. Strategic purchasing aims to increase health system performance through the effective allocation of financial resources to providers. This process involves three sets of explicit decisions:

- Which interventions should be purchased in response to population needs and wishes, taking into account national health priorities and evidence on cost-effectiveness

- How they should be purchased, including contractual mechanisms and payment systems

- From whom they ought to be purchased in light of providers' relative levels of quality and efficiency ${ }^{2}$

Strategic purchasing should lead to a maximization of overall health gain from available resources (i.e., increased allocative efficiency). It addresses one of the main problems traditionally encountered by health planners: bridging the gap between plans and the budgetary allocation of resources. For instance, in many tax-funded systems of the national-health-service (NHS) type, separate departments carry out these functions, with national health plans having little influence over the historical and incremental budgetary processes. ${ }^{3}$ Purchasing theory thus underlies the potential of this function when it is closely linked to the planning process.

This was one of the most important considerations when, in the United Kingdom (UK), Spain, Sweden and other tax-funded systems, the purchaser-provider split was developed and introduced in the early 1990s. Until then, these systems were regarded as integrated systems in which a single organization filled both the third-party payer and provider roles (e.g., the NHS in the UK). If organized at the national level (rather than at the regional level as, for example, in Sweden), these two functions were also intertwined with the ministry of health's regulatory role. Financial resources were typically allocated down the health service hierarchy and providers were under NHS command and control. The purchaser-provider split not only separated the two functions but also made both sides independent of direct (national) government control. The purchasing role was given to regional governments (e.g., in Spain and Italy) or to separate institutions (e.g., in the $\mathrm{UK}$ ), while providers were transformed into autonomous public entities ("trusts" in the UK). Somewhat later in most of these countries, purchasers also entered into purchasing relationships with other providers, both private not-for-profit and for-profit ones.

The basic NHS relationship between purchasers, providers and the government as steward and regulator has thus become similar to the traditional arrangement of actors in countries with a social health insurance (SHI) system, often termed Bismarckian after the 
German chancellor at the time when the first SHI system was introduced by law in 1883 . In SHI countries, the role of third-party payers has been delegated to "sickness funds," which are separate from providers - be they public (typically owned by regional or local governments), private not-for-profit or for-profit. To a varying degree, national (and partly regional) governments regulate and supervise sickness funds and providers, both of which are organizationally separate from the regulating level government (Busse et al. 2004).

As to the question of whether the separation of purchasing and providing will bring net gains, at least in terms of economic efficiency, organization theory highlights a number of important factors. Markets appear to perform well when there is a potential for high competition, when investments do not tie providers to specific purchasers, when complexity and uncertainty are relatively low and when few scale economies apply. The absence of these conditions in healthcare, however, has led attention to shift toward network models. These can involve partnership models, which retain purchaser-provider separation but encourage long-term relationships and integrated decision-making. The relational contracts that are used in most network models rely on trust in order to economize on transaction costs. Network models resonate closely with the political ideas of the "third way," which has been described as an explicit rejection of both the old centralized command-and-control systems and of divisive market systems. The third way seeks to find a middle path that combines a commitment to social values with some of the benefits believed to flow from an entrepreneurial approach. The obvious question arising from third-way approaches in the healthcare arena is whether the practice of purchasing meets these theoretical expectations.

\section{Citizen Empowerment}

A central element in purchasing theory is that a purchaser agent represents the wishes and needs of its citizenry. Strategies for citizen empowerment in purchasing can be grouped under the following four strategies:

- Assessing population health needs

- Ascertaining citizens' views and values

- Enforcing purchasers' accountability

- Increasing citizens' choices

It should be noted at the outset that these strategies are aimed primarily at increasing health systems' responsiveness but also, to the extent they reflect population health needs, at improving health, equity and allocative efficiency. However, as we note below, this is not always the case and trade-offs between these objectives are usually necessary. One other preliminary consideration here is that, in addition to these mechanisms that strengthen downward accountability to the population, patient empowerment is also achieved through upward accountability of purchasers and providers to health systems' stewards (i.e., democratically elected governments).

\section{Assessing Population Health Needs}

In spite of its widely recognized importance, health needs assessment is not routinely carried out in many health systems; when it exists, it is not always incorporated into purchasing decisions. These shortcomings are due to a variety of reasons, including the general deficiency of the public health function in many countries, the non-geographically delimited coverage of many purchasers (e.g., sickness funds in many SHI countries) and the scarcity of public health skills in purchasing organizations, particularly those with small population coverage. Above all, they reflect the lack of structural or functional 
integration of the public health function within purchasing. This function seems to work better in NHS systems in which coordination or integration between public health and purchasing is more straightforward; however, in some NHS countries there is still a virtual absence of health needs assessment. In spite of the inherent difficulties in SHI systems that, for instance, compartmentalize preventive and curative activities, the introduction of some innovative structures (e.g., in France) allowing for formal coordination between actors has met with positive results (Sandier et al. 2004).

\section{Ascertaining Citizens' Views and Values}

Purchasers' decisions often do not reflect their societies' values. There are, however, a number of innovative experiences in Norway, Sweden, the Netherlands and the UK on which one can draw in order to include citizens' views when deciding which services to provide (Mossialos and Maynard 1999). These examples are not exempt from complexity. For instance, citizens' participation in determining packages of care has proven to be problematic. Citizens are frequently averse to reducing care priorities and their views often lack consistency. In addition, we should take into account the fact that the influence of social values on purchasing priorities does not necessarily increase equity and allocative efficiency; as a consequence, trade-offs are at times necessary. ${ }^{4}$

\section{Enforcing Purchasers' Accountability}

There are four ways in which purchasers can be made accountable to their populations:

- Formal representation

- Statutory establishment of packages of care

- Patients' rights legislation

- Complaint mechanisms
The formal representation of consumers in purchasing organizations is commonplace in many European countries. The challenge lies in determining which group best represents consumers on purchasing boards. Another major strategy for enforcing purchasers' accountability is the statutory establishment of packages of care with formal coverage guarantees. This is very much the practice in most Western European SHI systems (Gibis et al. 2004) but less so in the more recently developed SHI systems in Eastern Europe and in many of the NHS systems in northern and southern Europe. A key means of enhancing the role of consumers in purchasers' decision-making and ensuring accountability is to stipulate purchasers' rights and responsibilities. In recent years there has been a flurry of national and international patients' rights conventions and declarations. Most countries have also developed patients' rights legislation, while others have developed patients' charters or ethical codes. One last mechanism to enforce purchasers' accountability and responsiveness to consumers is the use of complaint mechanisms to influence individual purchaser decisions. This is particularly so in many SHI systems where, due to the contractual relationships involved, complaints are raised before civil or administrative courts or made to quasi-judicial bodies. Most NHS systems have also put in place complaint systems; however, the absence of legally enforceable entitlements in many of them reduces the scope for consumers to assert whether the provision - or, more likely, the non-provision - of a particular service was appropriate.

\section{Increasing Citizens' Choice}

The strategies for citizen empowerment outlined above correspond, in Hirschman's (1970) terminology, to "voice" mechanisms. Health systems also increasingly rely on exit 
mechanisms, notably the choice of purchaser and/or provider, as the ultimate strategy to empower individuals. Consumers in most countries have the right to choose their primary care providers. In SHI systems, consumers may also choose ambulatory specialists and hospitals (albeit in some countries - such as the Netherlands - through a gate-keeper). Choices are more restricted in NHS systems; however, this is rapidly changing in many countries. Swedish and Norwegian patients, for example, are allowed to choose any hospital outside their county of residence. Patients under the jurisdiction of the English NHS have also seen their hospital choices increased. While increased consumer choice of providers clearly increases responsiveness, there is debate over its negative impact on other social objectives, notably equity, cost containment and allocative efficiency. There is evidence that choice tends to benefit the higher (and usually betterinformed) social classes and thus may lead to increasing health inequalities. The policy response, however, should not necessarily be to reduce choice in line with the "equity in poverty" argument but, rather, to focus efforts to ensure wider access to information and to support choice among the underprivileged.

\section{Strengthening Government Stewardship}

There is broad consensus among analysts and policy-makers about the central role of government stewardship in ensuring health system effectiveness. Stewardship's main functions include formulating strategic policy directions, generating intelligence, exerting influence through regulation and ensuring accountability (Saltman and Ferroussier-Davis 2000; Travis et al. 2003).

The central question for policy-makers is no longer whether strengthening stewardship of purchasing is necessary but how to put it in place. A preliminary consideration is the level of government at which purchasing stewardship should occur (i.e., central government's role vis-à-vis regional or local levels and accountability mechanisms). On the whole, devolution to lower levels of government tends to increase responsiveness to local needs. It can, however, decrease equity of access - especially for some minority groups - and efficiency due to lack of economies of scale and duplication of facilities.

\section{Translating Health Policy into Purchasing Decisions}

Formulating health policy is a key function of government stewardship but one that is either absent or poorly carried out in many countries. As a result, it has tended to have minimal influence over purchasing decisions. The following five policy lessons can be drawn from the analysis of the failures, as well as successes, in implementing health targets:

- Targets should be realistic but challenging (not the mere projection of trends), transparent, technically and politically plausible, evidence-based, selective and reflective both of health needs and priorities.

- Key stakeholders, particularly the professionals involved in implementation, should be included in setting targets.

- Targets should be supported with evidence for effective implementation policies.

- Sub-national development of targets in combination with national formulation increases the likelihood of their implementation.

- Building targets into performancemanagement systems, including financial incentives and performance reviews, also facilitates their implementation. 


\section{Establishing an Integrated Regulatory Framework}

Regulation takes centre stage in health systems' adoption of purchasing structures. These structures typically involve the substitution of hierarchical managerial relationships with contracts, management decentralization and a plurality of public and private providers, all of which require increased regulation. There is a wide array of regulatory mechanisms available to decision-makers to ensure purchasing's effective functioning.

The first lesson for policy-makers is to achieve an appropriate balance between proentrepreneurial regulation and regulation that sets boundaries to individual entrepreneurial behaviour. Sometimes the development of purchasing is stifled by a host of constraining regulations that lack mechanisms to facilitate entrepreneurship (e.g., enabling independent purchasing organizations and self-governance of public providers or introducing performance-based payment systems). The opposite has also been true in countries where command-and-control mechanisms have quickly been dismantled without an appropriate regulatory framework in place. This has caused opportunistic behaviour by both providers and purchasers, to the detriment of social objectives. A complementary policy lesson is, therefore, that deregulation should not occur without simultaneous re-regulation (Saltman and Busse 2002).

Purchasing's intricate components require a multi-level effort to achieve policy objectives. Perverse consequences result from narrow regulatory efforts focused on single purchasing components (e.g., payment systems) or on economic concerns (e.g., cost control). Another general lesson is, therefore, that one ought to be able to regulate complexity by setting out a broad framework of regulations that integrates and coordinates the various aspects of cost-effective purchasing and deals with multiple objectives.

The main regulatory mechanisms that should be part of such a framework are grouped into four main categories. First, there are regulations to ensure citizens' participation and purchasers' accountability. Such regulations provide for the availability of information from purchasers about access to health services, formal participation of citizen representatives on purchasing boards, patients' rights legislation stipulating what citizens can expect from purchasers and complaint mechanisms, including an ombudsperson (den Exter 2005; Hunter et al. 2005).

Second, certain regulatory mechanisms are aimed at monitoring purchasers' performance. One set of regulations focuses on their insurance role, guaranteeing equitable and efficient behaviour and including mandatory insurance with open enrolment, income-related contributions or community-rated premiums and the transfer of funds between purchasers (applying redistribution formulae to compensate for differences in the risk structure) (Rice and Smith 2002). Another set of regulations relates to purchasing and aims to ensure operation within a fixed budget, a standardized package of benefits and government participation on purchasing boards.

The third type of regulation addresses the contractual relationships between providers and purchasers. This entails setting up a framework and rules for collective contracting; specifying the roles of the various partners, including purchasers, associations of providers, professional organizations and the government; and establishing the details of the contracting process, including negotiation and litigation rules. Specific rules and procedures for contracting include requirements for access to information for purchasers and providers as well as the right of purchasers to 
evaluate the implementation of contractual provisions, quality standards, payment-system requirements and price regulation via national tariffs by unit of output, such as a diagnosisrelated group (DRG), or by requiring specific costing and pricing procedures.

A fourth set of regulatory mechanisms is directed mainly at providers. It includes measures affecting strategic planning, technology and licensing, certification and accreditation.

\section{Strengthening Government's Capacity and Credibility}

Governments face a series of technical, economic, political and cultural barriers that impinge on their ability and credibility to carry out effective purchasing stewardship (Hunter et al. 2005). First of all, the technical and administrative abilities required are lacking, particularly in some of the countries in Central and Eastern Europe (CCEE). When regulatory departments exist, they are often understaffed and have poor information about the behaviour of purchasers and providers. Moreover, there are substantial transaction costs involved in formulating health policies and, particularly, in setting a regulatory framework, collecting information and monitoring purchasers. Although these costs should be offset by the efficiency gains derived from a well-functioning purchasing system, they still pose an economic obstacle for some governments.

The gap between the public guarantees of healthcare delivery and the public funding available poses a larger economic and political obstacle. For instance, the violation by governments of their own obligations to finance healthcare services weakens their control over purchasers. Political obstacles are further increased by the inability of some governments to enforce statutes and by the divergence of policies among different government bodies.

Many countries also face cultural and organizational difficulties in realizing purchas- ing stewardship. Among these are the existence of closed social networks between government officials, purchasers and providers, alliances that might prevent the enforcement of legal agreements. Moreover, in some countries the former management culture of officials accustomed to command-and-control functions might prevent them from adapting to their new stewardship role.

\section{Ensuring Cost-Effective Contracting}

Contracts are the main vehicle by which purchasers translate their populations' health needs and desires into the provision of health services.

\section{Linking Contracting with Planning}

Establishing a purchasing strategy is the starting point of the contracting process (Duran et al. 2005). More emphasis should be paid to requiring purchasers to develop strategic (long-term) and operational (annual) purchasing plans. These will signal purchasers' intentions by setting out service requirements, budget constraints and performance targets. They will also enable providers to produce their own business plans. The contracting cycle continues with purchasers identifying and selecting providers, followed by negotiating contracts, reaching agreement and then managing and monitoring those contracts. The way this process is conducted depends on the degree of competition involved.

An appropriate balance must also be maintained between government stewardship and the roles of purchasers and providers in negotiating contracts' main parameters, such as activities (e.g., number of patients treated, surgeries performed), payment methods and selection of providers. In some countries government determines these parameters. As a result, the contracting parties are left with a merely symbolic role, making contracting a bureaucratic process. 


\section{Ensuring Evidence-Based Contracts}

Part of the rationale for introducing contracts is to implement evidence-based healthcare by incorporating best-practice guidelines. In reality, however, this potential is far from realized and contracts often make little or no reference to evidence-based practices.

The first step in evidence-based contracting is to ensure that the actual evidence is available to purchasers. Most Western European governments have some form of health technology assessment (HTA) in the form of national agencies, although this is less the case in the CCEE, where HTA is less common (Borowitz et al. 2004). These initiatives have yielded many valuable insights; however, they often focus on individual technologies and interventions rather than on the overall organizational framework of care within which the interventions are used. Overall, there is still little research that can provide the information purchasers need, despite its availability and good quality (McKee and Brand 2005).

The second step is to incorporate evidence on interventions and methods of service delivery into workable contracts for specific disease and client groups. This step entails developing treatment guidelines that account for existing practices, the potential for change and the resources required and a broad view of health improvement, including both prevention and treatment options. This is an area of major potential but it is manifestly underdeveloped in most countries. One exception is the UK's NHS frameworks, which provide a comprehensive approach to building health strategy, priority interventions, treatment guidelines and performance targets into contracts.

\section{Moving toward Cost-and-Volume Contracts}

Decision-makers often face the question of what type of contract is the most appropriate. Issues of capacity and feasibility are paramount in their decisions. On the whole, however, there seems to be a common trend toward service (cost-and-volume) and performance-based contracts. SHI countries in Western Europe are increasingly adopting more complex forms of cost-and-volume contracts, particularly ones that define products and include performance indicators. European NHS systems, at the start of the purchaser-provider split reforms, adopted block contracts that have become progressively sophisticated by incorporating better definitions of volume and product. Many of the CCEE, when they introduced SHI based on contracts, began with retrospective forms of cost-per-case contracts aimed at increasing activity; given upward cost pressures, however, they have also been increasingly moving toward cost-and-volume contracting. Such contracts seem to have the most potential for signalling the appropriate incentives to providers because they allow purchasers to decide the volume of care required, to define the product and to determine cost-effective forms of intervention. At present, however, most of these contracts are still relatively unsophisticated.

\section{Paying for Performance}

A system of payment, with its built-in financial incentives, is the main mechanism for contract implementation, to the extent that often there is little difference between a contract and the payment system it involves. An optimal payment system should induce providers to deliver top-quality treatments that respond to patients' needs with a high degree of technical efficiency. However, no single payment system seems to achieve all of them and trade-offs frequently become necessary. Retrospective methods of reimbursing providers by fee-for-service and/or per diems increase service productivity as well as responsiveness but can have a negative impact 
on cost containment and efficiency. When providers are reimbursed for finished cases through some case-mix measure, the incentive is to treat cases more efficiently; however, problems with allocative efficiency and cost containment remain. This is not to say, however, that the answer lies simply in introducing prospective global budgets.

Many Western European countries have adopted a form of global budget based on prospective levels of activity and adjusted for severity through some case-mix measure such as DRG or one of its variants. Most countries

\section{Policy-makers, therefore, might prefer to opt for more transparent and easy-to- implement systems rather than more sophisticated systems that have greater potential but that face greater implementation and monitoring challenges.}

also have an additional payment component based on retrospective cost-per-case reimbursement, usually for particularly expensive treatments or for cases handled by providers that lack contractual agreements with their purchasers.

Within this broad convergence in payment models, there is still much diversity involving aspects such as the choice of case-mix measure to adjust for severity and the use of financial incentives to reach target levels of efficiency and quality. Many methodological aspects also remain unresolved. A main methodological debate concerns the definition and measurement of the healthcare product, which has led to the development of a host of case-mix measures such as DRGs, patient-management categories (PMCs) and disease staging. A more complex methodological challenge is how to pay for the treatment of diseases that require various episodes of care at different levels. Another area that requires further emphasis and methodological innovation is linking payment incentives to quality indicators set out in contracts; for instance, providers' adherence to standards of care or fulfilling a series of health outcome and responsiveness targets.

In sum, there is broad convergence toward global budgets based on activity levels, which are adjusted by the severity of patients' health status, and on performance targets. In other words, such budgets incorporate inputs (severity), processes (activity) and outcomes (performance). However, a number of unresolved methodological issues require further innovation and development. A note of caution about the limits of payment systems is also pertinent here. Incentives often act as a double-edged sword: they can be easily "gamed" by providers who invariably have better information than purchasers (Rochaix et al. 1998). In addition, excessive reliance on payment systems can detract from investing efforts in other possibly effective strategies. Moreover, there are important trade-offs in terms of the transaction costs and management skills required to implement complex payment systems. Policy-makers, therefore, might prefer to opt for more transparent and easy-to-implement systems rather than more sophisticated systems that have greater potential but that face greater implementation and monitoring challenges.

\section{Promoting Quality through Contracts}

Quality strategies can be examined in relation to the stages in the contracting process, including negotiating (specifying appropriate quality requirements); monitoring (requiring and checking provider quality reports or 
getting feedback from the public); and reviewing (agreeing on changes to improve quality via the contract) (Velasco-Garrido et al. 2005).

Prior to entering into a contract, a purchaser can establish a series of quality requirements and pre-select only those providers who fulfill them. At a minimum, purchasers should contract only with licensed facilities and personnel; purchasers might also set higher standards and contract only with certified personnel and accredited providers.

Accreditation measures have been developed mostly in the United States (US) and, although they have attracted interest in Europe, have been implemented there on a relatively small scale and with limited impact. In the CCEE, requiring provider accreditation and certification as preconditions for contracts has resulted in significant improvements in the quality of hospital infrastructure and care.

A more effective approach is to specify a series of quality requirements in contracts. These can be enforced through regulations, sanctions and/or payment incentives. There are three main types of quality requirements (Velasco-Garrido et al. 2005):

- Standards of care: These (e.g., mandating providers to use a particular set of clinical guidelines) are particularly useful in cases where evidence is sound and uncontroversial (e.g., adherence to diabetes care guidelines).

- Quality assurance initiatives: Clinical governance in the UK is an example.

- Quality targets (process and outcome): Process targets can entail levels of provision or wait times for certain interventions. Outcome targets can use surrogate measures such as blood pressure levels (if clearly correlated with patient-relevant outcomes) or patient-relevant outcome targets such as mortality from certain conditions (e.g., myocardial infarction).
In addition to specifying quality requirements in contracts, performance monitoring is central to achieving improved quality. There is a need for regionally or nationally coordinated schemes, particularly when there is competition between purchasers and providers and a provider is likely to contract with several purchasers at the same time.

\section{With or without Provider Competition?}

Most countries that discussed or introduced new forms of purchaser-provider separation during the 1990s did so on the basis that there would be supply-side competition. Competition was to be the market-based lever for improved performance. In practice, however, competition did not always materialize as theorists and policy-makers intended. In some ways this was entirely predictable. For one thing, healthcare markets are characterized by strong elements of spatial monopoly (resulting from patients' inability or unwillingness to travel), making competition difficult to achieve. In addition, it became clear (e.g., with the advent of the internal market in the UK in 1991) that the political consequences of market failure - resulting from supply-side competition - would be unacceptable.

It also became clear that transaction costs could make supply-side competition expensive; ways of economizing on these were, therefore, often sought. As a result, a number of countries attempted to encourage longerterm collaborative arrangements between purchasers and providers. This raises the question of whether contracting can operate effectively when purchasers do not have a choice of providers. On one hand, the contracting process in itself is a mechanism for purchasers and providers to be more explicit about mutual expectations than would otherwise be the case. On the other hand, if a purchaser cannot, in a case of unsatisfactory service from an existing provider, move to an alternative 
provider, the stimulus for provider efficiency is seriously compromised.

One possible way out of this conundrum is to rely on proxy competition. Regulators can benchmark provider performance and require change in the case of persistent failure. Additionally, it is possible to draw on the concept of contestability; that is, new entrants to a market (e.g., through franchising arrangements) might pose a threat to existing providers even if actual competition does not exist.

\section{Implementing Contracting}

A common set of political, financial, managerial and organizational obstacles can hinder contracting implementation. The first major obstacle is the high complexity of most contracting mechanisms. The major complexities are the design of contracts, the development of appropriate payment systems, the specification of quality requirements and the monitoring of performance. All of these require a high level of managerial and technical skill, together with wide-ranging information systems that are not available to some purchaser organizations in several Western European countries, let alone in less developed Eastern European countries. Moreover, these mechanisms are very resource intensive, a factor that can pose an economic barrier to their implementation. The establishment of a contracting system, therefore, needs to be preceded by an assessment of purchasing organizations' capacities and, when required, by investing in appropriate training programs and information systems.

In some countries, the organizational design and roles of purchasers and providers might also pose major obstacles to implementation. These include fragmentation of purchasing, poor complementarity of design among strategies, inappropriate organizational definitions of purchaser and provider roles and institutional (legal and administrative) imped- iments (Duran et al. 2005; Langenbrunner et al. 2005).

Issues also arise involving design complementarity among different strategies that provide incongruent incentives (e.g., financial ones) that are inconsistent with the quality indicators specified in a contract. Sometimes these problems apply to specific strategies (e.g., the adoption of payment mechanisms across settings) that do not complement one another and, therefore, undermine allocative efficiency.

Inappropriate definition of purchasers' functions is also likely to hinder contract implementation. In particular, there is much uncertainty about the roles of purchasers in the implementation of strategies such as health needs assessment, health strategy development, provider accreditation and development of specification guidelines for quality indicators in contracts.

Issues germane to organizational coherence also apply to provider organizations involved in contracts. For contracting to function properly, providers must have sufficient managerial and financial flexibility in order to respond to a contract's demands and incentives (discussed in the section on providers below). Further organizational reform of purchasers and providers is often blocked by institutional - legal or administrative - impediments. Many new models of purchasing organizations (both for purchasers and providers) have no chance of taking root unless they are preceded by a broader reform of the civil service and the public sector in which they are to be based.

Political and cultural issues comprise the third category of implementation obstacles. For instance, ministries of health often have vested political interests in not delegating decision-making to purchaser organizations, particularly in areas such as the selection and contracting of providers. 


\section{Developing Appropriate Purchasing Organizations}

\section{Finding the Right Purchaser}

An important distinguishing feature of the range of purchaser organizations found in different European countries is the nature of their vertical organization (Robinson et al. 2005). This can involve macro, meso or micro levels of purchasing. Given this variety, the obvious question is what level of purchasing is likely to be most effective? Methodological difficulties in tracing causes and effects, coupled with the weakness of empirical evidence, make it difficult to offer an unambiguous answer. Moreover, the history of the health service organizations in a given country and their current institutional structures act as powerful constraints on feasible purchasing models. Clearly, a one-size-fits-all recommendation is untenable.

It is possible, however, to make some observations that policy-makers should take into account, albeit with a clear eye to their own national and/or regional and local situations. One is that devolution of decisionmaking seems to be associated with a number of advantages. Macro-level purchasing rarely offers the managerial autonomy necessary to improve local decision-making. The new public management seeks to give managers the opportunity to manage rather than to act as inflexible bureaucrats. This is far easier to achieve within lower-level organizations, where entrepreneurship and innovation can be expected to follow. Similarly, responsiveness to patients and the public is likely to increase as purchasing decisions are taken closer to users. Contracting also becomes a more effective mechanism because negotiations take place between local decision-makers. Nonetheless, it must be recognized that some functions require a strong national focus (e.g., public health goals and the pursuit of equity targets).

\section{Choosing between Multiple Purchasers}

One of the most powerful ideas to influence public policy during the 1980s and 1990s was the belief that markets and competition have the capacity to improve efficiency. In Europe, proposals to extend consumers' choices of insurer/purchaser and to allow greater competition among purchaser organizations have sought to avoid the excesses of the US managed care system (Smith et al. 2005). In the Netherlands, for example, policies designed to increase competition between insurers and sickness funds have devoted considerable effort to the derivation of appropriate risk-adjustment formulae in order to avoid adverse risk selection.

Notwithstanding these developments in the Netherlands (as well as in Germany and Switzerland), the most striking finding to emerge from our study is that, despite the considerable pro-competition rhetoric that has characterized health service debates in Europe in recent years, the overwhelming majority of purchasing organizations continue to operate in non-competitive environments. Sometimes this occurs because macro-purchasers are, by definition, monopoly purchasers. In other cases, effective competition is made difficult because purchasers are territorially based. In yet other cases, the requirement for purchasers to make standard packages of care available reduces the dimensions over which competition can operate.

Does the absence of demand-side competition matter? To those who argue that choice and competition are powerful stimulants for improved provider responsiveness and increased efficiency, the absence of competition is a cause for concern. However, if a country's institutional structure does not lend itself to purchaser competition or if the downside of competition (e.g., reduced equity and increased transactions costs) is considered too great, alternative mechanisms can be used 
to achieve similar ends. Overall, there does not seem to be a strong case for relying on demand-side competition as a mechanism for improving purchaser performance (Maarse et al. 2005).

\section{Improving Provider Performance}

Bearing in mind the timing of most purchasing reforms, it is too early to make firm policy conclusions. Nonetheless, it is possible to draw some general lessons about the main factors and conditions that influence providers' responses to purchasing.

\section{Increasing Provider Autonomy}

Institutional providers in Europe vary greatly in their degree of autonomy. Limited autonomy and flexibility to respond to new contracting incentives have been major causes of purchasing failure in many countries.

To achieve greater hospital autonomy (see Harding and Preker 2000) and hence more flexibility for providers to respond, policymakers can extend decision-making rights over key areas such as hiring and firing; determining the number of staff members and their skill mix; financial management (e.g., the ability to take loans); determining the level and scope of activities; and making decisions about capital development, including ones related to numbers of beds and technology. Moreover, decision can increase market exposure by introducing some form of provider market competition combined with a regulation of residual claims in such a way that "leftover" resources remain with providers (Saltman and Busse 2002).

\section{Making Providers More Accountable}

There are several mechanisms to ensure managerial accountability linked to the contracting process. Purchasers can negotiate performance targets with providers, monitor the extent to which these have been achieved and, if the targets have not been achieved, amend or terminate contractual agreements.

Public accountability means that providers must also communicate the results of their performance to patients and the public. Information such as numbers of patients treated, complication rates, wait times and procedures completed can be made accessible via media such as consumer journals, Web sites, newspapers and/or hospital-based publications. Emphasis is growing on the systematic and independent measurement of provider performance. This is increasingly used in countries to benchmark performance across providers (e.g., via hospital leagues). Provider autonomy must be accompanied by increased transparency, and these efforts are likely to continue and grow.

\section{Managing a New Power Balance}

The introduction of purchasing - and its subsequent increase in provider autonomy - results in a different balance of power and incentives among purchasers, providers and consumers. Policy-makers need to be aware of the range of provider responses to these new balances. These responses might be positive or negative depending on whether providers see the introduction of purchasing as an opportunity or a threat.

Providers might respond to new power balances in a structural or a tactical manner. An example of a structural response is a merger with other providers to increase market power. Tactical responses refer to how a provider operates in a concrete contracting process with a provider. Provider behaviour might be entirely opportunistic and contrary to system-wide objectives (e.g., by increasing activities in order not to miss out on extra resources) but can also be in line with a system's objectives of equity, effectiveness and efficiency. Contracting out, creating integrated healthcare delivery networks and developing 
initiatives to reduce wait times are examples of such provider-driven responses. The strength of provider-driven responses will depend on each provider's ambitions (in this regard, a distinction should be made between pioneers, followers and conservatives).

A final distinction resides among political, judicial and managerial responses. A political response, in particular, has caused the failure of purchasing in many European countries. Providers often mobilize political resources to increase pressure on a purchasing agency and to influence the contracting process in their favour.

\section{Conclusions}

Analysis of many European countries shows, not surprisingly, diverse approaches to purchasing (Figueras et al. 2005). There are, however, some clear common trends.

The various approaches undertaken across Europe reveal that reform efforts must focus on strengthening purchasers' ability to respond to consumer needs and to establish more cost-effective contracts with providers. Concurrently, without capable government stewardship, strategic purchasing is bound to fail. Government needs to provide clear leadership by formulating health policies and establishing a set of health targets that can guide purchasing decisions and provide a basis on which to evaluate its overall impact. The high complexity of strategic purchasing also requires putting in place a comprehensive regulatory framework that integrates and coordinates purchasing's various components. This framework must achieve a fine balance between regulation that favours and limits entrepreneurial behaviour so as to ensure the attainment of health system objectives.

The political, technical and financial ability to implement strategic purchasing is the most important factor determining its success. Most, if not all, of the strategies we have reviewed in this paper are complex and require a high level of technical and managerial skills, together with wide-ranging information systems that are lacking in many countries. In addition, strategic purchasing leads to new power balances among key stakeholders and, therefore, it might often face major political obstacles to implementation. This possibility calls for an incremental approach to implementing strategic purchasing, one that uses pilot experiments to test the most complex strategies and limits, at the outset, the scope of purchasing to some services as well as builds political consensus to ensure purchasing's sustainability.

\section{Endnotes}

1 This chapter summarizes the topics developed in depth in Figueras et al. (2005).

2 These explicit decisions are an expansion of the discussion by the World Health Organization (2000).

3 In this paper we distinguish between the uppercase National Health Service found in the UK and the similar lower-case national-health-service type of system found in several other countries. For convenience, we employ the initialism NHS to refer to both; in every case, our meaning is readily apparent from the contexts.

4 The results of citizen consultations and debate on priorities in Sweden are reflected in a series of guidelines (McKee and Figueras 1996).

\section{References}

Borowitz, M., R. Massoud and Martin McKee. 2004. "Improving the Quality of Health Systems." In J. Figueras, M. McKee, J. Cain and S. Lessof, eds., Health Systems in Transition: Learning from Experience. Copenhagen: WHO for the European Observatory on Health Systems and Policies.

Busse, R., R.B. Saltman and H.F.W. Dubois. 2004. "Organization and Financing of Social Health Insurance Systems: Current Status and Recent Policy Developments." In R.B. Saltman, R. Busse and J. Figueras, eds., Social Health Insurance Systems in Western Europe. Maidenhead: Open University Press.

den Exter, A.P. 2005. "Purchasers as the Public's Agent.” In J. Figueras, E. Jakubowski and R. Robinson, eds., Purchasing to Improve Health Systems Performance. Maidenhead: Open University Press. 
Duran, A., I. Sheiman, M. Schneider and J. Øvretveit. 2005. "Purchasers, Providers and Contracts." In J. Figueras, E. Jakubowski and R. Robinson, eds., Purchasing to Improve Health Systems Performance. Maidenhead: Open University Press.

Figueras, J., E. Jakubowski and R. Robinson, eds. 2005. Purchasing to Improve Health Systems Performance. Maidenhead: Open University Press.

Gibis, B., P.W. Koch-Wulkan and J. Bultman. 2004.

"Shifting Criteria for Benefit Decisions in Social Health Insurance Systems.” In R.B. Saltman, R. Busse and J. Figueras, eds., Social Health Insurance Systems in Western Europe. Maidenhead: Open University Press.

Harding, A. and A.S. Preker. 2000. "Organizational Reform in the Hospital Sector: A Conceptual Framework." In A.S. Preker and A. Harding, eds., Innovations in Health Care Reform: The Corporatization of Public Hospitals. Baltimore: Johns Hopkins University Press.

Hirschman, A. 1970. Exit, Voice and Loyalty. Cambridge: Harvard University Press.

Hunter, D.J., S. Shishkin and F. Taroni. 2005.

"Steering the Purchaser: Stewardship and Government." In J. Figueras, E. Jakubowski and R. Robinson, eds., Purchasing to Improve Health Systems Performance. Maidenhead: Open University Press.

Langenbrunner, J., E. Orosz, J. Kutzin and M. Wiley. 2005. "Purchasing and Paying Providers." In J. Figueras, E. Jakubowski and R. Robinson, eds., Purchasing to Improve Health Systems Performance. Maidenhead: Open University Press.

Maarse, H., T.A. Rathwell, T. Evetovits, A.S. Preker and E. Jakubowski. 2005. "Responding to Purchasing Provider Perspectives" In J. Figueras, E. Jakubowski and R. Robinson, eds., Purchasing to Improve Health Systems Performance. Maidenhead: Open University Press.

McKee, M. and H. Brand. 2005. "Purchasing to Promote Population Health.” In J. Figueras, E. Jakubowski and R. Robinson, eds., Purchasing to Improve Health Systems Performance. Maidenhead: Open University Press.

McKee, M. and J. Figueras. 1996. "For Debate: Setting Priorities: Can Britain Learn from Sweden?" BMJ 312: 691-94.

Mossialos, E. and A. Maynard. 1999. "Setting Health Care Priorities: To Whom and on What Basis?" Health Policy 49(1).
Rice, N. and P. Smith. 2002. "Strategic Resource Allocation and Funding Decisions." In E. Mossialos, A. Dixon, J. Figueras and J. Kutzin, eds., Funding Health Care: Options for Europe. Buckingham: Open University Press.

Robinson, R., E. Jakubowski and J. Figueras. 2005. "Organization of Purchasing in Europe." In J. Figueras, E. Jakubowski and R. Robinson, eds., Purchasing to Improve Health Systems Performance. Maidenhead: Open University Press.

Rochaix, L. 1998. "Performance-Tied Payment Systems for Physicians.” In R.B. Saltman, J. Figueras and C. Sakellarides, eds., Critical Challenges for Health Care Reform in Europe. Buckingham: Open University Press.

Saltman, R.B and R. Busse. 2002. "Balancing Regulation and Entrepreneurialism in Europe's Health Sector: Theory and Practice." In R.B. Saltman, R. Busse and E. Mossialos, eds., Regulating Entrepreneurial Behaviour in European Health Care Systems. Buckingham: Open University Press.

Saltman, R.B. and O. Ferroussier-Davis. 2000. "The Concept of Stewardship." Bulletin of the World Health Organization 78(6): 733-39.

Sandier, S., V. Paris and D. Polton. 2004. Health Care Systems in Transition: France. Copenhagen: European Observatory on Health Systems and Policies.

Smith, P., A.S. Preker, D. Light and S. Richard. 2005. "Role of Markets and Competition." In J. Figueras, E. Jakubowski and R. Robinson, eds., Purchasing to Improve Health Systems Performance. Maidenhead: Open University Press.

Travis, P., D. Egger, P. Davies and A. Mechbal. 2003. "Towards Better Stewardship: Concepts and Critical Issues." In C.J.L. Murray and D.B. Evans, eds., Health Systems Performance Assessment Debates, Methods and Empiricism. Geneva: World Health Organization.

Velasco-Garrido, M., M. Borowitz, J. Øvretveit and R. Busse. 2005. "Purchasing for Quality of Care." In J. Figueras, E. Jakubowski and R. Robinson, eds., Purchasing to Improve Health Systems Performance. Maidenhead: Open University Press.

World Health Organization. 2000. World Health Report 2000. Health Systems: Improving Performance. Geneva: Author. 